\title{
Enteroviral meningitis reduces CSF concentration of $A \beta 42$, but does not affect markers of parenchymal damage
}

\author{
Kacper Toczylowski ${ }^{1} \cdot$ Malgorzata Wojtkowska $^{2} \cdot$ Artur Sulik $^{1}$ (D) \\ Received: 19 March 2019 / Accepted: 23 April 2019 / Published online: 15 May 2019 \\ (C) The Author(s) 2019
}

\begin{abstract}
Biomarkers classically studied in Alzheimer's disease have been analyzed in numerous central nervous system infections in adults, but there are scarce data on these biomarkers in children. Enteroviruses appear to be the most common cause of aseptic meningitis throughout the world. The aim of the study was to investigate neuroinflammatory properties of non-polio enteroviruses by measuring CSF concentrations of biomarkers that are involved in neuropathological pathways of neurodegenerative disorders. We measured $\mathrm{A} \beta 42$, $\mathrm{t}$-tau, and $\mathrm{S} 100 \mathrm{~B}$ concentrations in 42 children with enteroviral meningitis (EM) compared to control group without central nervous system infection. We found enteroviral meningitis (EM) to reduce CSF concentration of A 342 (median, $1051.1 \mathrm{pg} / \mathrm{mL}$; interquartile range (IQR), 737.6-1559.5 vs. median, $459.4 \mathrm{pg} / \mathrm{mL} ; \mathrm{IQR}, 312.0-662.0, p<0.001$ ). In contrast, CSF concentrations of t-tau and S100B were not affected by EM. There was a correlation between total neutrophil count in CSF and A $\beta 42(R=-0.59, p<0.001)$. Absolute number of mononuclear cells in the CSF correlated with CSF t-tau $(R=0.41, p<0.05)$. Both correlations remained significant after adjustment for age, blood leukocytes, serum CRP, CSF leukocytes, and CSF protein concentration.
\end{abstract}

Keywords Enteroviral meningitis $\cdot$ Children $\cdot$ Meningitis $\cdot$ Biomarkers $\cdot$ Amyloid $\cdot$ Tau proteins

\section{Introduction}

Enteroviruses are ubiquitous, and most individuals encounter at least one of these viruses at some time in their lives. The overwhelming majority of viral meningitis cases of any ages are caused by non-polio enteroviruses. Given non-polio enteroviruses are so common and they are known to exhibit strong neurotropism, it is well worth analyzing brain injury following enteroviral central nervous system (CNS) infection.

Artur Sulik

artur.sulik@umb.edu.pl

Kacper Toczylowski

kacper.toczylowski@umb.edu.pl

Malgorzata Wojtkowska

m.wojtkowska@vp.pl

1 Department of Pediatric Infectious Diseases, Medical University of Bialystok, Waszyngtona 17, 15-274 Bialystok, Poland

2 Department of Pediatric Laboratory Diagnostics, Medical University of Bialystok, Waszyngtona 17, 15-274 Bialystok, Poland
Biomarkers classically studied in neurodegenerative disorders such as Alzheimer's disease (AD) are being investigated in CNS infections of bacterial and viral origin $[1,2]$. Traditionally AD is characterized by accumulation of amyloid $\beta$ plaques and neurofibrillary tangles [3]. The two hallmark features still leave a gap in the understanding of AD pathogenesis. Substantial evidence now indicates that inflammation is playing a key role in $\mathrm{AD}$ [4]. Over the past decades, a number of infectious agents, including viruses of Herpesviridae family, have been postulated to be involved in $\mathrm{AD}$ etiopathogenesis $[1,5]$. To date, little is known on enteroviruses influencing inflammatory pathways similar to those seen in AD. Currently, S100B is another emerging biomarker of blood-brain barrier (BBB) permeability and CNS injury. $\mathrm{S} 100 \mathrm{~B}$ is a calcium-binding protein produced predominantly by astrocytes in the brain. Elevated concentrations of CSF S100B were measured in various CNS pathologies [6, 7]. Interestingly, S100B levels in body fluids are elevated prior to clinical symptoms and imaging findings and may predict disease outcome or treatment efficacy $[6,8]$.

In the current study, we aimed at investigating neuroinflammatory properties of non-polio enteroviruses by measuring CSF concentrations of S100B and classic AD 
biomarkers: $\mathrm{A} \beta 42$, $\mathrm{t}$-tau in children with enteroviral meningitis (EM).

\section{Methods}

\section{Study design}

The study was conducted on children with meningitis caused by enteroviruses, who were hospitalized in the tertiary teaching hospital in Bialystok, Poland, during a single seasonal outbreak. The control group included children suspected of having a CNS infection, but evaluation of CSF ruled out the diagnosis.

\section{CSF measurements}

CSF samples were centrifuged and stored at $-80^{\circ} \mathrm{C}$ for analysis. Biomarker concentrations were measured with ELISA kits. A $\beta 42$ was analyzed using INNOTEST $\beta$ AMYLOID(1-42) ELISA kit (Fujirebio Diagnostics, Malvern, PA, USA). Total tau levels were measured with INNOTEST h-tau ELISA kit (Fujirebio Diagnostics, Malvern, PA, USA). Protein S100B was analyzed with Human S100B ELISA kit (Elabscience, Bethesda, MD, USA). Values below the detection limit were estimated as the detection limit divided by two.

\section{Statistical methods}

Statistical analysis was conducted using Statistica version 12 (TIBCO Software Inc.). Data are presented as median and interquartile range (IQR). Differences between the groups were analyzed using the Mann-Whitney $U$ test. Correlations were calculated using Spearman's rank correlation coefficient and adjusted using a general multiple regression model. A $p$ value of less than 0.05 was considered statistically significant.

\section{Results}

\section{Baseline characteristics}

Forty-two children with EM were included in this study. The diagnosis of EM was confirmed by the presence of increased cell count in the CSF ( $>5$ cells $/ \mu \mathrm{L}$ ) and the detection of enterovirus RNA in CSF $(n=40)$ or stool samples $(n=2)$. Viral culture followed by sequencing revealed echovirus 30 to be a single cause of the outbreak. The baseline characteristics of the study groups and main results are presented in Table 1.

\section{$A \beta_{42}, t-t a u$, and S100B in enteroviral meningitis}

Concentration of $\mathrm{A} \beta 42$ in CSF was significantly reduced in EM patients. Interestingly, CSF concentrations of t-tau and $\mathrm{S} 100 \mathrm{~B}$ were not affected by the infection (Fig. 1). The ratio of CSF t-tau $/ \mathrm{A} \beta_{42}$ increased in EM (Table 1).

\section{Correlations}

We did not find any significant correlations between the biomarkers and serum CRP, blood leukocytes, CSF leukocytes, or CSF protein concentration. However, CSF t-tau moderately correlated with $\mathrm{A} \beta 42$ in the EM group and controls (Fig. 2a, b). Correlations between S100B and two other biomarkers were insignificant. Age and gender were not related to the CSF biomarker profile.
Table 1 Demographic, laboratory, and CSF characteristics of the studied groups

\begin{tabular}{|c|c|c|}
\hline & Controls & EM \\
\hline No. of patients & 32 & 42 \\
\hline Age, years ${ }^{*}$ & $7.6(5.1-13.5)$ & $12.1(7.0-15.2)$ \\
\hline Female/male & $13 / 19$ & $12 / 30$ \\
\hline $\mathrm{CRP}, \mathrm{mg} / \mathrm{L}^{*}$ & $4.8(0.9-12.0)$ & $5.4(3.1-10.6)$ \\
\hline Blood leukocyte count $\times 10^{3} / \mu \mathrm{L}^{*}$ & $9.7(5.9-13.7)$ & $9.8(7.7-11.6)$ \\
\hline CSF leukocyte count $/ \mu \mathrm{L}^{*}$ & $1.0(1.0-1.5)$ & $109.0(47.0-196.0)^{* *}$ \\
\hline CSF protein, $\mathrm{mg} / \mathrm{dL}^{*}$ & $10.0(6.0-12.0)$ & $27.5(21.0-44.0)^{* *}$ \\
\hline CSF mononuclear cells $/ \mu \mathrm{L}^{*}$ & - & $63.6(46.5-117.8)$ \\
\hline CSF neutrophils $/ \mu \mathrm{L}^{*}$ & - & $27.7(5.9-106.1)$ \\
\hline $\mathrm{A} \beta 42, \mathrm{pg} / \mathrm{mL}^{*}$ & $1051.1(737.6-1559.5)$ & $459.4(312.0-662.0)^{* *}$ \\
\hline t-tau, $\mathrm{pg} / \mathrm{mL}^{*}$ & $380.7(233.5-518.6)$ & $270(164.8-396.2)$ \\
\hline $\mathrm{S} 100 \mathrm{~B}, \mathrm{pg} / \mathrm{mL}^{*}$ & $350.2(277.8-458.3)$ & $329.9(278.4-381.3)$ \\
\hline $\mathrm{t}$-tau/A $\beta 42$ ratio $^{*}$ & $0.32(0.25-0.54)$ & $0.54(0.38-0.87)^{* *}$ \\
\hline
\end{tabular}

$E M$, enteroviral meningitis; $C R P$, C-reactive protein; $C S F$, cerebrospinal fluid; $A \beta 42$, amyloid beta $42 ; t$-tau, total tau; $S 100 B, \mathrm{~S} 100$ calcium-binding protein B; ${ }^{*}$ Values expressed as median (interquartile range); ${ }^{* *} p<0.001$ 


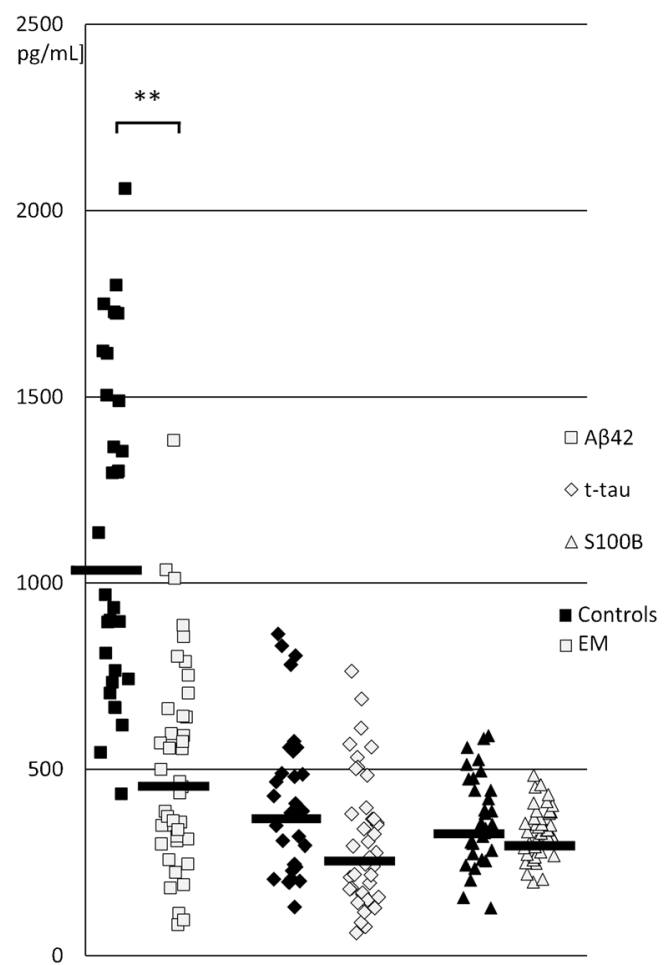

Fig. 1 Scatter plot of cerebrospinal fluid concentrations of amyloid beta 42 (A $\beta 42$, white square), total tau (t-tau, white diamond), and S100 calcium-binding protein $\mathrm{B}(\mathrm{S} 100 \mathrm{~B}$, white triangle) in enteroviral meningitis (EM) (white points) vs. controls (black points). Black horizontal lines represent median values. $* * p<0.001$
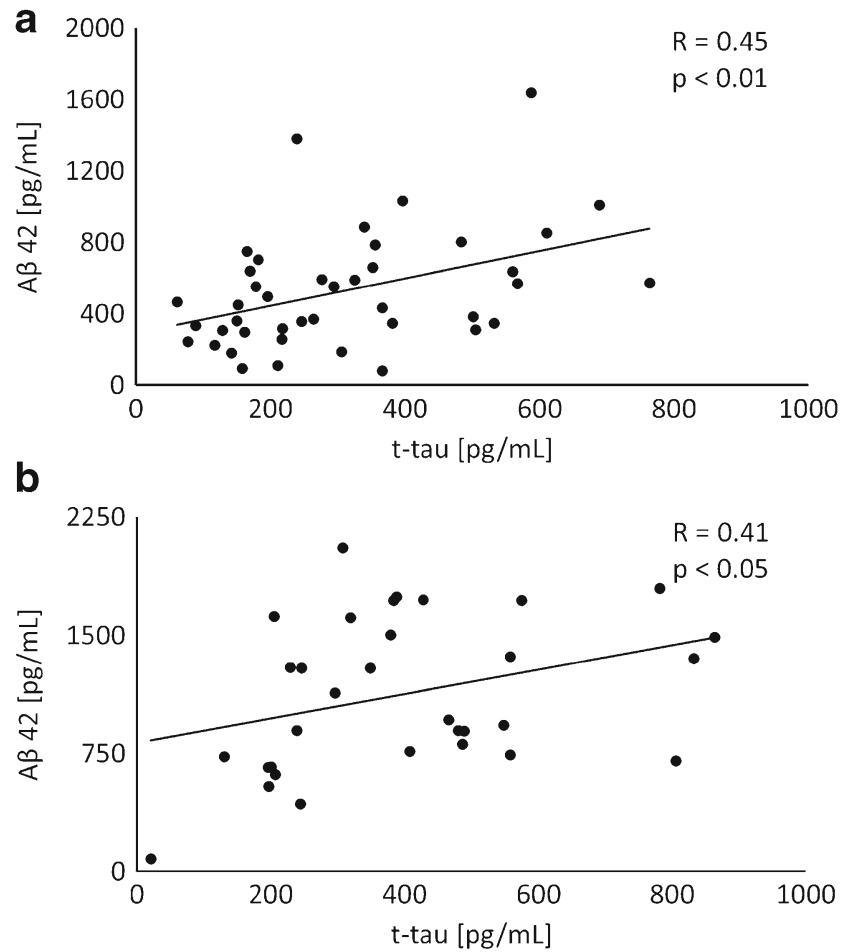

Fig. 2 Relationships between cerebrospinal fluid (CSF) concentrations of amyloid beta $42(\mathrm{~A} \beta 42)$ and CSF total tau (t-tau) in enteroviral meningitis (a) and healthy controls (b). R, correlation coefficient
The absolute number of neutrophils in CSF strongly and negatively correlated with CSF A $\beta 42$ in EM (Fig. 3a). There was a positive correlation between CSF mononuclear cells and CSF t-tau (Fig. 3b). These correlations remained significant after adjustment for age, blood leukocytes, serum CRP, CSF cell count, and CSF protein concentration. Concentration of S100B did not correlate with neutrophils or with mononuclear cells in the CSF.

\section{Discussion}

In this study, CSF A $\beta 42$ concentration was decreased in EM. Similar observations were made in bacterial meningitis and HSV-1 encephalitis [9-11]. The decrease may be explained by a lower production of amyloid $\beta$ peptides in the brain and disturbed clearance. The function of BBB is impaired in meningitis, allowing influx of proteins from the blood to the CSF. Possibly, serum proteins bind to $\mathrm{A} \beta 42$, affecting its detection; however, addition of serum to the CSF did not reduce $A \beta 42$ levels in one study [10]. Additionally, $A \beta 42$ has a direct antimicrobial activity and binds to various bacterial strains, what reduces its concentrations in $\mathrm{CSF}[12,13]$.
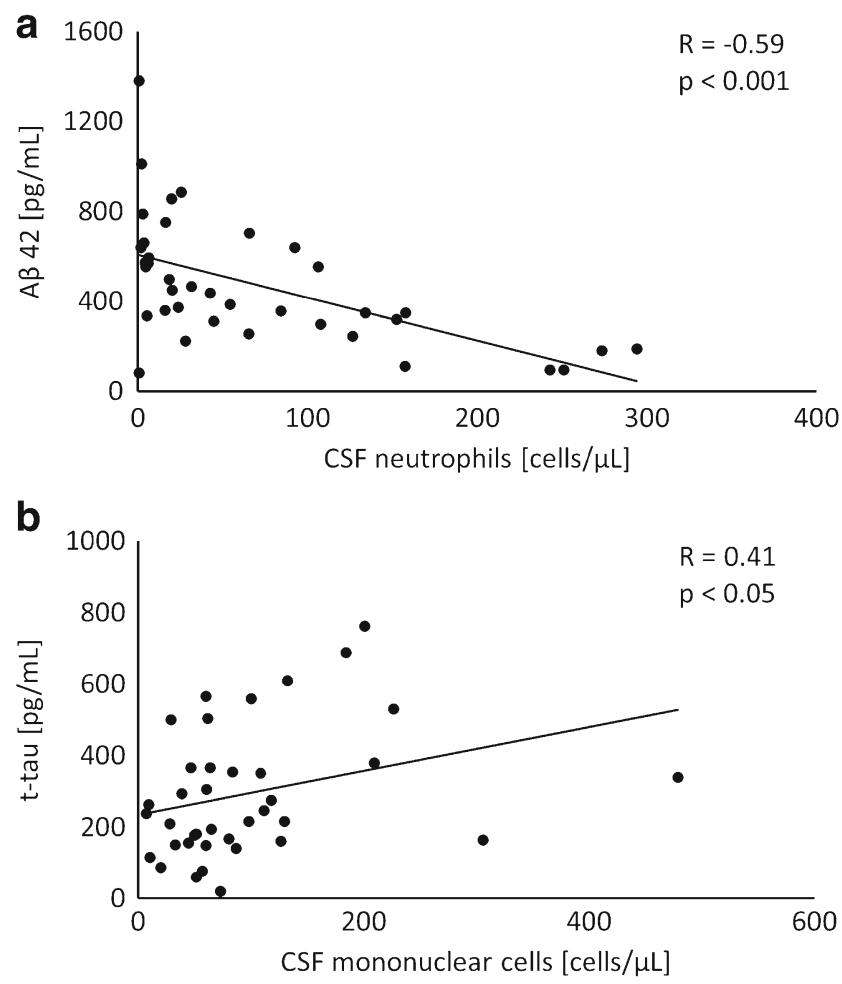

Fig. 3 Relationships between (a) cerebrospinal fluid (CSF) absolute neutrophil count and CSF concentrations of amyloid beta 42 (A $\beta 42$ ), and (b) between CSF absolute mononuclear cell count and total tau (t-tau) in enteroviral meningitis. R, correlation coefficient 
Tau concentration in the CSF is a marker of brain parenchymal damage. Increased CSF tau levels are observed in brain hemorrhage, traumatic brain injury, severe bacterial meningitis, and HSV-1 encephalitis [9, 14, 15]. Meningitis, however, does not always result in increased CSF tau levels [10, 14, 16]. For example, HIV-associated dementia and neuroborreliosis were associated with a decrease in CSF t-tau $[9,17]$. The extremely low levels of CSF t-tau were also observed in patients with GuillainBarre Syndrome in one study. Authors suggest that the observed decrease may have been caused by increased elimination or consumption of tau protein, because its detection is not influenced by BBB dysfunction [14]. As it was shown by Süssmuth, CSF tau concentrations were increased in CNS infections with encephalitic complications only [14]. In our study, CSF t-tau levels were not increased in the EM. Protein S100B, a marker of glial cell injury, was not affected as well. Elevated S100B levels are observed in encephalitis and bacterial meningitis, but remain unaltered in viral meningitis $[16,18]$. For example, CSF S100B levels over $960 \mathrm{pg} / \mathrm{mL}$ were associated with higher risk of brain injury in encephalitis of viral, bacterial, and unknown etiology [19]. Our results clearly indicate that meningitis caused by non-polio enteroviruses is not associated with a significant parenchymal damage.

We hypothesize that the correlations between CSF A $\beta 42$, $t$-tau, neutrophils, and mononuclear cells may reflect the natural course of inflammatory response in EM. Neutrophils can predominate early in the course of aseptic meningitis [20]. As the number of neutrophils drops, the number of mononuclear cells increases. Mononuclear cells infiltrating CNS in EM may possibly cause a slight parenchymal damage in EM reflected in t-tau concentrations. It may also explain decreased A $\beta 42$ levels, because bloodderived monocytes migrating into the CNS are key players in phagocytosis of $A \beta$ [21].

Interestingly, the t-tau/A $\beta 42$ ratio was higher in the EM group. The ratio over 0.52 was suggested to be a robust marker of an $\mathrm{AD}$ profile in the CSF [22]. Here, we show that an increased t-tau/A $\beta 42$ ratio is not specific for $\mathrm{AD}$ and may also be observed in viral meningitis. We also found positive correlations between $A \beta 42$ and t-tau concentrations in EM and healthy controls. This indicates that $A \beta 42$ is linked to $t$-tau. A coupling of tau to $A \beta$ oligomers in cognitively normal adults was reported before [23].

Several limitations of this study must be acknowledged. This is a cross-sectional study, so correlations we found do not necessary mean causation. This is, however, the first study to analyze CSF A $\beta 42$, t-tau, and S100B concentrations in children with aseptic meningitis. The infection was caused by a single etiological agent making the study group homogenous, aiding in data interpretation.

\section{Conclusions}

Our data suggest that there may be an important relation between cerebrospinal fluid leukocytes, A $\beta 42$, and t-tau. Previous studies have already acknowledged that CNS infections have an impact on biomarkers of neurodegeneration in CSF, but failed to give insights on underlying processes. Here, we report that neutrophils may play a role in amyloid metabolism, and that mononuclear cells are linked to t-tau concentrations in children with enteroviral meningitis.

Funding The study was founded by grant from Medical University of Bialystok, Poland.

\section{Compliance with ethical standards}

Ethics approval and consent to participate The study protocol was approved by the Research Ethics Committee of our institution. An informed written consent was obtained from all the children's parents or legal guardians.

Consent for publication All authors have read and approved the final manuscript.

Competing interests The authors declare that they have no competing interests.

Open Access This article is distributed under the terms of the Creative Commons Attribution 4.0 International License (http:// creativecommons.org/licenses/by/4.0/), which permits unrestricted use, distribution, and reproduction in any medium, provided you give appropriate credit to the original author(s) and the source, provide a link to the Creative Commons license, and indicate if changes were made.

\section{References}

1. Itzhaki RF (2017) Herpes simplex virus type 1 and Alzheimer's disease: possible mechanisms and signposts. FASEB J 31:32163226

2. Zhan X, Stamova B, Jin L-W, DeCarli C, Phinney B, Sharp FR (2016) Gram-negative bacterial molecules associate with Alzheimer disease pathology. Neurology 87:2324-2332

3. Buée L, Bussière T, Buée-Scherrer V, Delacourte A, Hof PR (2000) Tau protein isoforms, phosphorylation and role in neurodegenerative disorders. Brain Res Brain Res Rev 33:95-130

4. Kinney JW, Bemiller SM, Murtishaw AS, Leisgang AM, Salazar AM, Lamb BT (2018) Inflammation as a central mechanism in Alzheimer's disease. Alzheimers Dement (N Y) 4:575-590

5. Ashraf GM, Tarasov VV, Makhmutova A, Chubarev VN, AvilaRodriguez M, Bachurin SO, Aliev G (2018) The possibility of an infectious etiology of Alzheimer disease. Mol Neurobiol. https:// doi.org/10.1007/s12035-018-1388-y

6. Rohlwink UK, Mauff K, Wilkinson KA, Enslin N, Wegoye E, Wilkinson RJ, Figaji AA (2017) Biomarkers of cerebral injury and inflammation in pediatric tuberculous meningitis. Clin Infect Dis 65:1298-1307

7. Chaves ML, Camozzato AL, Ferreira ED, Piazenski I, Kochhann R, Dall'Igna O, Mazzini GS, Souza DO, Portela LV (2010) Serum 
levels of S100B and NSE proteins in Alzheimer's disease patients. J Neuroinflammation 7:6

8. Alshweki A, Pérez-Muñuzuri A, López-Suárez O, Baña A, Couce ML (2017) Relevance of urinary S100B protein levels as a shortterm prognostic biomarker in asphyxiated infants treated with hypothermia. Medicine (Baltimore) 96:8453

9. Krut JJ, Zetterberg H, Blennow K, Cinque P, Hagberg L, Price RW, Studahl M, Gisslén M (2013) Cerebrospinal fluid Alzheimer's biomarker profiles in CNS infections. J Neurol 260:620-626

10. Sjögren M, Gisslén M, Vanmechelen E, Blennow K (2001) Low cerebrospinal fluid beta-amyloid 42 in patients with acute bacterial meningitis and normalization after treatment. Neurosci Lett 314: 33-36

11. Spitzer P, Lang R, Oberstein TJ, Lewczuk P, Ermann N, Huttner HB, Masouris I, Kornhuber J, Ködel U, Maler JM (2018) A specific reduction in $\mathrm{A} \beta 1-42$ vs. a universal loss of $\mathrm{A} \beta$ peptides in CSF differentiates Alzheimer's disease from meningitis and multiple sclerosis. Front Aging Neurosci 10:152

12. Spitzer P, Condic M, Herrmann M et al (2016) Amyloidogenic amyloid- $\beta$-peptide variants induce microbial agglutination and exert antimicrobial activity. Sci Rep 6:32228

13. Soscia SJ, Kirby JE, Washicosky KJ et al (2010) The Alzheimer's disease-associated amyloid beta-protein is an antimicrobial peptide. PLoS One 5:9505

14. Süssmuth SD, Reiber H, Tumani H (2001) Tau protein in cerebrospinal fluid (CSF): a blood-CSF barrier related evaluation in patients with various neurological diseases. Neurosci Lett 300:95-98

15. Collins-Praino LE, Corrigan F (2017) Does neuroinflammation drive the relationship between tau hyperphosphorylation and dementia development following traumatic brain injury? Brain Behav Immun 60:369-382
16. Jung K, Goerdt C, Lange P, Blocher J, Djukic M, Gerber J, Spreer A, Nau R, Otto M, Schmidt H (2011) The use of S100B and tau protein concentrations in the cerebrospinal fluid for the differential diagnosis of bacterial meningitis: a retrospective analysis. Eur Neurol 66:128-132

17. Mattsson N, Bremell D, Anckarsäter R, Blennow K, Anckarsäter H, Zetterberg H, Hagberg L (2010) Neuroinflammation in Lyme neuroborreliosis affects amyloid metabolism. BMC Neurol 10:51

18. Gazzolo D, Grutzfeld D, Michetti F, Toesca A, Lituania M, Bruschettini M, Dobrzanska A, Bruschettini P (2004) Increased S100B in cerebrospinal fluid of infants with bacterial meningitis: relationship to brain damage and routine cerebrospinal fluid findings. Clin Chem 50:941-944

19. Peng Q-L, Tao S-H, Yu N, Zhou X-Z, Peng Y-Z, Fu N (2017) Elevated levels of cerebrospinal fluid S100B are associated with brain injury and unfavorable outcomes in children with central nervous system infections. Int J Neurosci 127:1-9

20. Negrini B, Kelleher KJ, Wald ER (2000) Cerebrospinal fluid findings in aseptic versus bacterial meningitis. Pediatrics 105:316-319

21. Hohsfield LA, Humpel C (2015) Migration of blood cells to $\beta$ amyloid plaques in Alzheimer's disease. Exp Gerontol 65:8-15

22. Duits FH, Teunissen CE, Bouwman FH et al (2014) The cerebrospinal fluid "Alzheimer profile": easily said, but what does it mean? Alzheimers Dement 10:713-723 e2

23. Handoko M, Grant M, Kuskowski M, Zahs KR, Wallin A, Blennow K, Ashe KH (2013) Correlation of specific amyloid- $\beta$ oligomers with tau in cerebrospinal fluid from cognitively normal older adults. JAMA Neurol 70:594-599

Publisher's note Springer Nature remains neutral with regard to jurisdictional claims in published maps and institutional affiliations. 